\title{
Correction of tracheo-cutaneous adhesion after tracheostomy
}

\author{
Soh Nishimoto*, Yohei Sotsuka, Kenichiro Kawai and Masao Kakibuchi \\ Department of Plastic Surgery, Hyogo College of Medicine, 1-1 Mukogawa-cho, Nishinomiya, Hyogo 663-8131, Japan
}

\begin{abstract}
Tracheostomy is indicated for various situations to secure airway. After decanulation, the secondary intention is regularly employed and contraction of tissue will lead to heal. Frequently, an indented scar remains. Simple revision of the scar or classic Poulard's method of burying deepithelized scar is utilized to ease the cosmetic problems. Though in some severe cases, re-adhesion of trachea and cervical skin occurs, because of the lack of soft tissue between them. Tight contracture burden patients with pain in phonation and swallowing. A simple procedure of turning over dermal-fat flaps, to augment subcutaneous tissue between trachea and overlying skin, was applied to five cases. All procedures were performed under local anaesthesia. The procedure could solve the functional problems with acceptable cosmetic results.
\end{abstract}

\section{Introduction}

Tracheostomy is required in various situations to secure airway. Prolonged tracheostomy or infection causes loss of subcutaneous tissue and scar formation around the orifice. The secondary intention method is often employed after the tube removal. Contraction will repair the wound. After that, a depressed scar is often seen. In mild cases, simple revision of the scar or classic Poulard's method [1] of burying deepithelized scar can ease the cosmetic problems. Though, in severe cases, adhesion of trachea to the cervical skin is so tight that the patients suffer pain in phonation and swallowing. Because of the pain, the patients can speak brokenly and weakly. They complain that a meal takes long time. In those patients, revision of the scar with simple fore mentioned procedures ends in re-adhesion of the trachea with skin, because of the lack of subcutaneous tissue. There can be seen some reports about correcting depression of the scar [2,3] including Poulard's [1] but not very much has been reported about easing functional problems. In this paper, a simple method of augmenting subcutaneous tissue bulk by turning over dermal-fat flaps to prevent re-adhesion applied to five cases is described.

\section{Surgical procedures (Figure 1)}

The procedures were conducted under local anesthesia. A spindle shape area with horizontal axis, including post-tracheostomy scar was deepithelized. Along the border of the deepithelized area, incision of dermis, down to the subcutaneous fat was made. Two flaps, with dermis and subcutaneous fat were raised like butterfly wings. Central part was left untouched to keep base for the blood supply. The dermal-fat flaps were turned over and folded one on the other, atop of the trachea. They were sutured with absorbable threads. Cephalic and caudal adjacent area was undermined as skin flaps. At this moment, relief of trachea from skin was confirmed. The spindle shaped skin defect was simply closed over the folded dermal-fat flaps. The sutured line fit with the relaxed skin tension line of the neck.

\section{Case report}

Cases treated with this procedure are summarized in Table 1.

\section{Case 2 (Figure 2)}

A 35-year-old lady was diagnosed as oropharynx cancer. She underwent tracheostomy, followed by cancer resection and free rectus abdominis musculo-cutaneous flap. She also underwent postoperative radiation therapy. Intubation period prolonged for three months. Scar excision and direct closure was done by primal surgeon. Though, contracture between trachea and skin became obvious. The patient complained of pain in phonation and swallowing. Correction of tracheo-cutaneous adhesion was done under local anesthesia. Immediately after the surgery, the patient felt relief from the pain. She was able to speak more strongly than before.

\section{Case 3 (Figure 3)}

A 33-year-old pregnant woman was diagnosed as lingual cancer. Tracheostomy, hemi-glossectomy and free antero-lateral thigh flap transfer were done. The secondary intention method was employed after decanulation. Two months later she gave birth to a healthy child. A year later, she was annoyed by throat pain in swallowing. Under local anesthesia, correction of the scar was done. The patient was satisfied with both functional and cosmetic result.

Cases treated with this procedure is summarized in Table.1

\section{Discussion}

Prolonged tracheostomy intubation, infection and so on can lead atrophy of the skin and subcutaneous soft tissue around the stoma. Secondary intention method is adopted in most of the cases after decanulation. Wound healing can be adopted mostly by contraction.

Correspondence to: Dr. Soh Nishimoto, Department of Plastic Surgery, Hyogo College of Medicine, Mukogawa-cho, Nishinomiya, Hyogo, Japan; Tel: 81-79845-6753; Fax: 81-798-45-6975; E-mail: nishimot@hyo-med.ac.jp

Key words: tracheostomy, scar, contracture, adhesion, dermal-fat flap

Received: June 05, 2016; Accepted: July 01, 2016; Published: July 04, 2016 

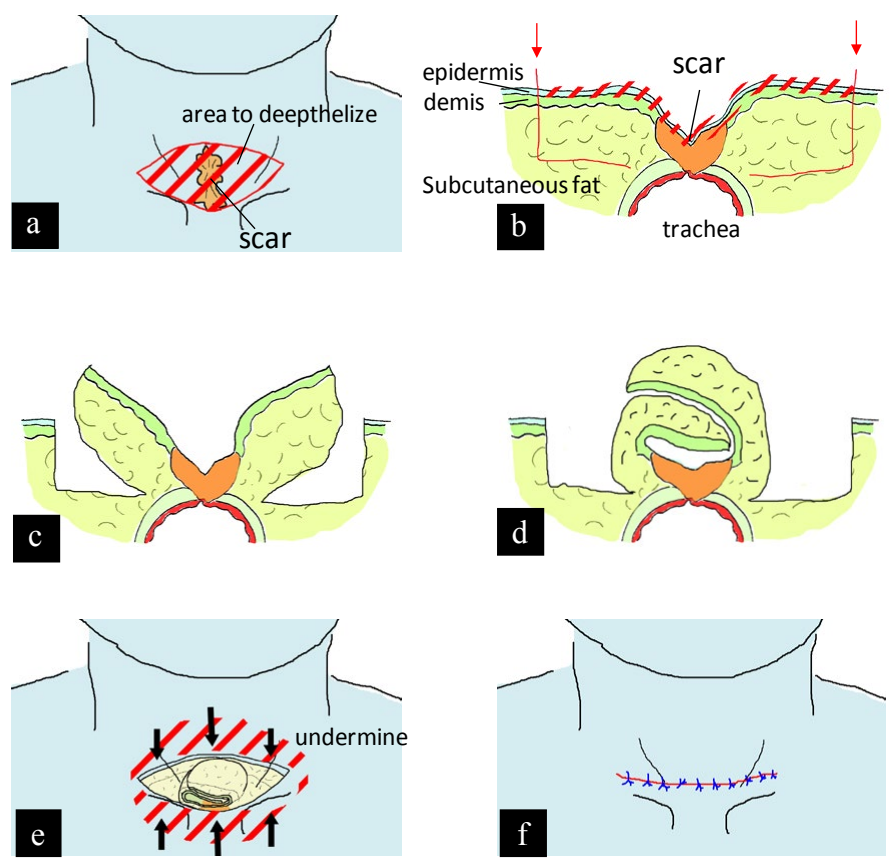

Figure 1. Schematic presentation of our procedure

a Spindle shape area was deepithelized.

$\mathrm{b}$ Incision to raise dermal-fat flaps.

c Two dermal-fat flaps were raised like butterfly wings.

$\mathrm{d}$ The flaps were rolled on top of the trachea.

e Adjacent area was undermined.

f Skin was approximated over the dermal flaps. The skin closure line would fit cervical relaxed skin tension line.
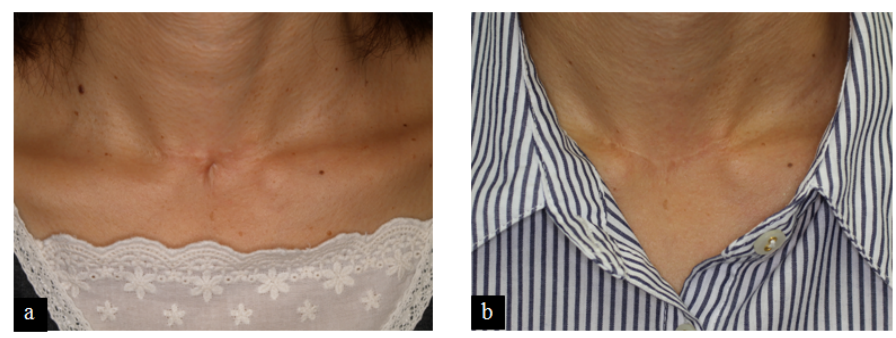

Figure 2. a. Pre-operative view of a 35 -year-old lady. There can be seen horizontal scar and re-adhesion of trachea with skin. b. Two years after the surgery.
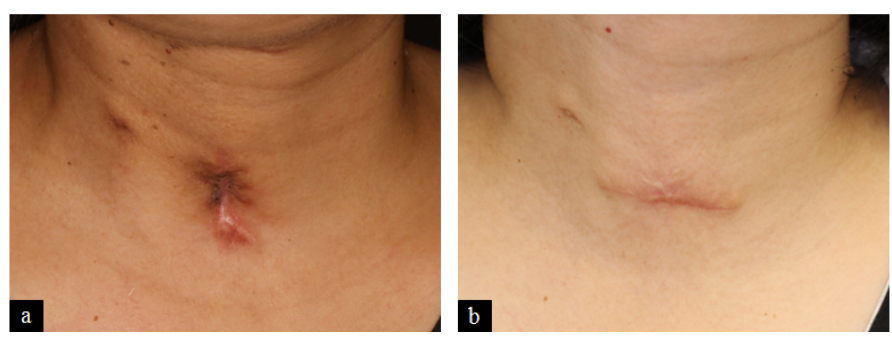

Figure 3. a. Indented scar with tight adhesion of trachea with skin can be seen. b. Two years after the surgery.

Scar formation on the trachea develops into direct adhesion of it with skin. Depressed scar will remain.

\begin{tabular}{|c|c|c|c|}
\hline Case No. & Age & Gender & Diagnosis \\
\hline 1 & 65 & F & lingual cancer \\
\hline 2 & 35 & F & oropharynx cancer \\
\hline 3 & 33 & F & lingual cancer \\
\hline 4 & 31 & F & trauma \\
\hline 5 & 63 & F & deep neck infection \\
\hline
\end{tabular}

Table 1. Summary of cases treated.

There have been several reports about correcting depression of posttracheostomy scar. Poulard [1] as early as in 1918, described a method. Incision was made around the depressed scar. Deepithelization of the circumcised scar tissue was done. The dermal layer and deep cicatricial core was left behind. And adjacent skin was undermined to make skin flaps. Those flaps were approximated over the scar, which was buried. Later, this method was modified by Lewin and Keunen [2]. They tubed the deepithelized scar island. In the other case, they folded edges of the circumcised scar tissue, one on top of the other. Hwang et al.[3] reported cosmetically successful cases with this method.

Another concept was to excise scar completely and to bring sternal head of sternocleidomastoid muscles together [4] or platysmal flap [5], filling defect. These methods require considerably wide and deep dissection.

The other was to use dermal fat graft [6] or allogenic materials $[7,8]$ Those materials lack vascularity, which can be a concern and some of these materials may be too thin to provide sufficient volume. In severe cases with post-tracheostomy scar, vertical movement of the trachea is limited by contraction. Patients complain pain in phonation and swallowing. They have to face burden in conversation, singing, eating and swallowing. Simple revision of the scar or Poulard's [1] method cannot solve the problems, because of the shortage of soft tissue between the overlying skin and trachea.

Our method is a modification of previously-cited Lewin and Keunen's [2], which is a descendant of Poulard's [1]. To provide ample soft tissue to buffer between trachea and skin, deepithelized buried flaps are extended laterally, where subcutaneous soft tissue is intact. It is a minor modification but has not been mentioned in previous literatures. Although skin closure line will be longer, it is usually acceptable, fitting relaxed skin tension line. This is a simple yet effective procedure with high degree of patient satisfaction.

\section{Acknowledgements}

Authors declare no conflict of interest associated with this manuscript. There is no particular funding source.

\section{References}

1. Poulard A (1918) Traitement de cicatrices faciales. Press Med 26: 221

2. Lewin ML, Keunen HF (1970) Revision of the posttracheotomy scar. Correction of the depressed, retracted scar. Arch Otolaryngol 91: 395-397. [Crossref]

3. Hwang S-M, Lee S-H, Kim H-I, Jung Y-H, Kim H-D (2013) Application of Bilateral De-epithelialized Hinge Flap to Correct the Deep Depressed Scar. Arch Aesthetic Plast Surg 19: 136-140.

4. Pressman JJ (1961) The Repair of Depressed Tracheotomy Scars. Arch Otolaryngol Head Neck Surg 74: 150-152.

5. Panse N, Sahasrabudhe P, Joshi S, Telang R (2011) Platysmal book flap for tracheostomy scars. Indian J Plast Surg 44: 526-528. [Crossref]

6. Stanton DC, Kademani D, Patel C, Foote JW (2004) Management of post-tracheotomy scars and persistent tracheocutaneous fistulas with dermal interpositional fat graft. $J$ Oral Maxillofac Surg 62: 514-517. [Crossref] 
7. Skigen AL, Bedrock RD, Stopperich PS (1999) Correction of the depressed, retracted, post-tracheostomy scar. Plast Reconstr Surg 103: 1703-1705. [Crossref]
8. Lu V, Johnson MA (2004) Tracheostomy scar revision using acellular dermal matrix allograft. Plast Reconstr Surg 113: 2217-2219.[Crossref]

Copyright: $\left({ }^{\circ} 2016\right.$ Nishimoto S. This is an open-access article distributed under the terms of the Creative Commons Attribution License, which permits unrestricted use, distribution, and reproduction in any medium, provided the original author and source are credited. 